EESTI NSV TEADUSTE AKADEEMIA TOIMETISED. KEEMIA

ИЗВЕСТИЯ АКАДЕМИИ НАУК ЭСТОНСКОИ ССР. ХИМИЯ

PROCEEDINGS OF THE ACADEMY OF SCIENCES OF THE ESTONIAN SSR. CHEMISTRY

$1984,33,1$

А. ААРНА, В. ВАСИЛЬЕВ, Ю. ЖИРЯКОВ

удК 620.193 .94

\title{
О КАТАЛИЗЕ И ИНГИБИРОВАНИИ ТЕРМИЧЕСКОЙ ДЕСТРУКЦИИ УГЛЕВОДОРОДОВ
}

Изучение катализа и ингибирования термической деструкции углеводородов приобретает все более важное значение в связи с возрастанием роли технологических процессов, основанных на избирательном температурном разложении одних органических веществ и синтезе других.

Ранее нами было показано, что при вторичном пиролизе нефтяного и сланцевого сырья, с целью получения ароматических углеводородов, существенную роль в деструктивных процессах играет содержание сернистых соединений в пиролизуемом сырье, а также качество материала пирозмеевика $\left[{ }^{1-3}\right]$. При этом отмечалось, что наибольшей каталитической активностью в процессах разложения углеводородов до кокса обладают окислы железа и никель, а активным ингибитором является меркаптановая и тиофеновая сера.

Для изучения промежуточных этапов деструктивных процессов в условиях катализа и ингибирования нами был поставлен ряд опытов по пиролизу индивидуальных углеводородов и промышленной смеси. Эксперименты проводили на лабораторной пиролизной установке, которая включала: систему дозирования, проточный 'кварцевый реактор, в котором электропечью СУОЛ поддерживалась температура $700 \pm 3{ }^{\circ} \mathrm{C}$, и систему конденсации с выводом пиролизного газа на газовый счетчик. Катализаторы $\mathrm{Fe}_{2} \mathrm{O}_{3}$ и $\mathrm{Ni}$ вносили в изотермическую зону реактора в фарфоровых лодочках, инкибитор - сланцевый бензин полукоксования - добавляли к сырью. Выбор данного ингибитора обусловлен тем, что в нем содержится до $1 \%$ серы, представленной меркаптанами и тиофеном, а также его способностью предотвращать в промышленных условиях коррозию пирозмеевика и не допускать снижения уровня коксообразования. Бензин добавляли в количестве, необходимом для поднятия содержания общей серы в пиролизуемом сырье на уровень $0,1 \%$, что соответствует неагрессивному течению деструктивных процессов $\left[{ }^{4}\right]$.

Продукты пиролиза охлаждали в трех последовательно соединенных конденсаторах, погруженных в криогенную смесь. Количество образовавшегося кокса учитывали весовым методом, состав пиролизного газа определяли хроматографически. При проведении опытов мы предполагали существование определенной связи между характером деструктивных процессов и видом пиролизуемого сырья на фоне катализа и ингибирования. Для проверки предположений пиролизу подвергали представителей различных классов углеводородов: парафины - гептан, гексан, октан, нонан; диеновые - пиперилен; ароматические - бензол, а также углеводородную смесь, являющуюся сырьем промышленной установки пиролиза ПО «Сланцехим», имеющую следующий групповой состав: парафиновые углеводороды $10-15 \%$, олефиновые + диеновые $18-25 \%$, ароматические $60-70 \%$. Состав жидких продуктов пиролиза изучали методом ЯМР-спектроскопии. 


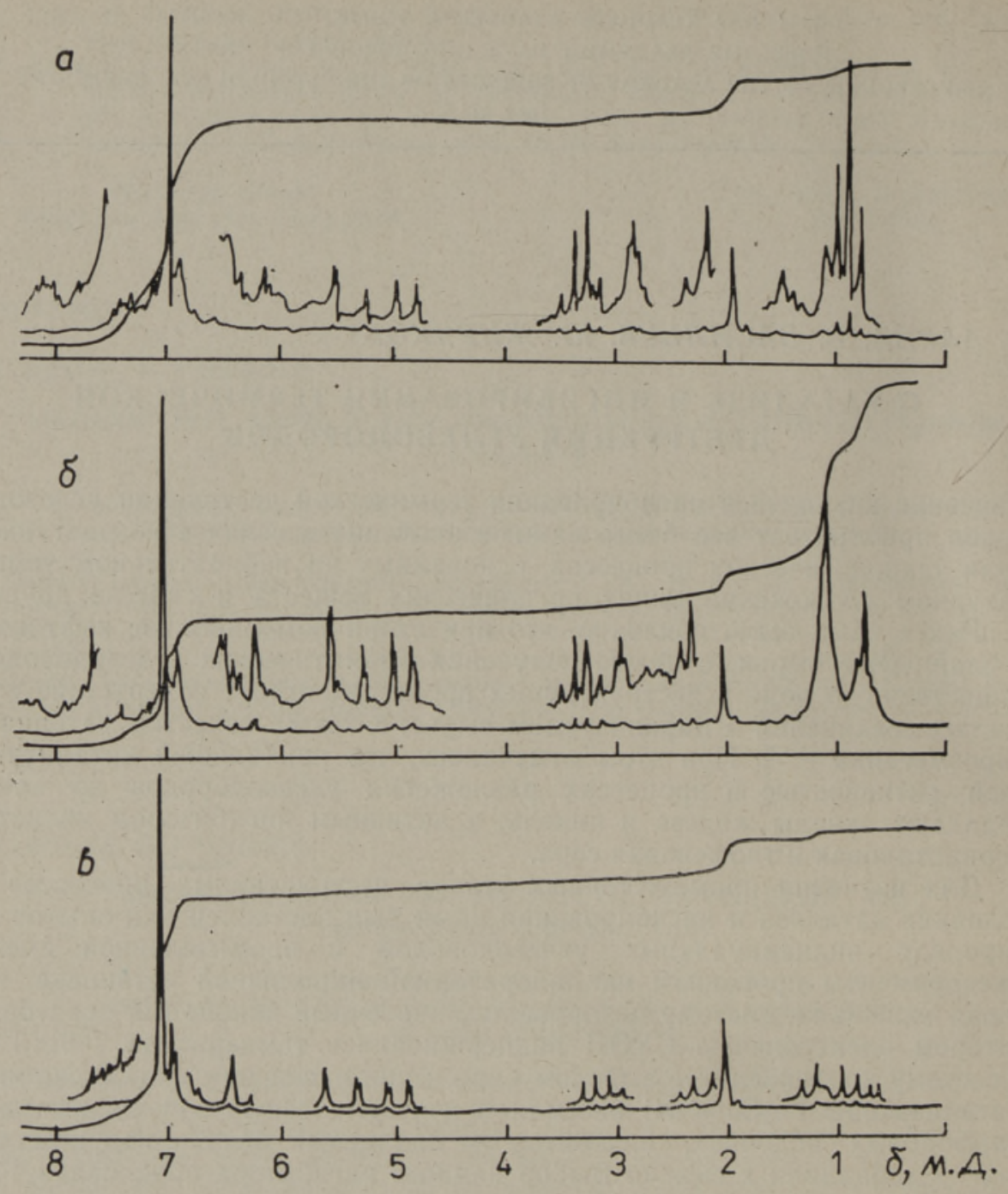

Рис. 1. Спектры протонного магнитного резонанса пиролизатов: пиперилена $(a)$, гептана (б) и промышленного сырья $(8)$.

Спектры протонного магнитного резонанса (ПМР) снимали на ЯМРспектрометре «Tesla BS-467». В качестве растворителя иопользовали четыреххлористый углерод. Внутренним стандартом служил гексаметилдисилоксан. Качественная картина ПМР-спектров пиролизатов вышеперечисленных продуктов существенно не менялась при замене катализатора. Поэтому спектры, приведенные на рис. 1, являются типичными. Из рис. $1, a$ видно, что наиболее интенсивные сигналы в спектре отвечают бензолу $\left(7,07\right.$ м. д.) и толуолу $\left(6,97(\mathrm{Ar}), 2,02\left(\mathrm{CH}_{3}\right)\right.$ м. д.), а полосы меньшей интенсивности соответствуют этилбензолу (6,97 (Ӓ), 3,30 $\left(\mathrm{CH}_{2}\right), 0,88\left(\mathrm{CH}_{3}\right)$ м. д.) и пиперилену (область $4,6-5,7$ м. д.). Кроме того, имеется еще серия слабых сигналов полиароматических, непредельных (олефинов) и алифатических структур, строение которых трудно определить в общей смеси. В спектре пиролизатов гептана и промышленного сырья (см. рис. $1,6,8$ ) также есть линии, характерные для бензола и толуола, непредельных и алифатических соединений, отличающихся лишь содержанием в смеси, 
Пиролиз индивидуальных углеводородов и промышленного сырья в зависимости от условий опыта. Температура пиролиза $700^{\circ} \mathrm{C}$ (здесь и далее в таблицах)

\begin{tabular}{|c|c|c|c|c|c|}
\hline $\begin{array}{c}\text { Сырье } \\
\text { пиролиза }\end{array}$ & Условия & 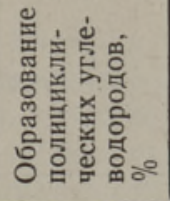 & 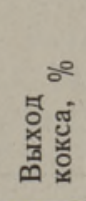 & 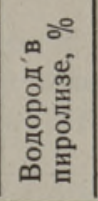 & 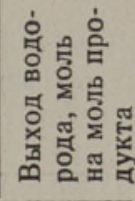 \\
\hline Гексан & $\begin{array}{l}\text { Без добавки } \\
\mathrm{C} \text { бензином полукоксования } \\
\mathrm{C} \mathrm{Fe}_{2} \mathrm{O}_{3} \\
\mathrm{C} \mathrm{Ni}\end{array}$ & $\begin{array}{l}0,53 \\
1,2 \\
3,9 \\
0,52\end{array}$ & $\begin{array}{l}4,9 \\
4,9 \\
5,0 \\
4,8\end{array}$ & $\begin{array}{r}12,8 \\
7,2 \\
30,0 \\
3,1\end{array}$ & $\begin{array}{l}0,11 \\
0,05 \\
0,19 \\
0,04\end{array}$ \\
\hline Гептан & $\begin{array}{l}\text { Без добавки } \\
\mathrm{C} \text { бензином полукоксования } \\
\mathrm{C} \mathrm{Fe}_{2} \mathrm{O}_{3} \\
\mathrm{C} \mathrm{Ni}\end{array}$ & $\begin{array}{l}0,9 \\
0,45 \\
4,2 \\
1,8\end{array}$ & $\begin{array}{l}1,4 \\
1,9 \\
1,7 \\
3,9\end{array}$ & $\begin{array}{l}19,0 \\
15,2 \\
29,9 \\
15,9\end{array}$ & $\begin{array}{l}0,39 \\
0,35 \\
0,52 \\
0,45\end{array}$ \\
\hline Октан & $\begin{array}{l}\text { Без добавки } \\
\mathrm{C} \text { бензином полукоксования } \\
\mathrm{C} \mathrm{Fe}_{2} \mathrm{O}_{3} \\
\mathrm{C} \mathrm{Ni}\end{array}$ & $\begin{array}{l}0 ; 33 \\
2,2 \\
5,9 \\
0,7\end{array}$ & $\begin{array}{l}1,8 \\
2,6 \\
1,3 \\
2,8\end{array}$ & $\begin{array}{r}10,4 \\
6,9 \\
34,3 \\
7,6\end{array}$ & $\begin{array}{l}0,08 \\
0,08 \\
0,27 \\
0,07\end{array}$ \\
\hline Нонан & $\begin{array}{l}\text { Без добавки } \\
\mathrm{C} \text { бензином полукоксования } \\
\mathrm{C} \mathrm{Fe}_{2} \mathrm{O}_{3} \\
\mathrm{C} \mathrm{Ni}\end{array}$ & $\begin{array}{l}0,36 \\
1,9 \\
4,4 \\
0,50\end{array}$ & $\begin{array}{l}3,0 \\
3,0 \\
1,1 \\
3,2\end{array}$ & $\begin{array}{r}14,2 \\
8,4 \\
24,5 \\
8,3\end{array}$ & $\begin{array}{l}0,32 \\
0,26 \\
0,43 \\
0,29\end{array}$ \\
\hline Пиперилен & $\begin{array}{l}\text { Без добавки } \\
\mathrm{C} \text { бензином полукоксования } \\
\mathrm{C} \mathrm{Fe}_{2} \mathrm{O}_{3} \\
\mathrm{C} \mathrm{Ni}\end{array}$ & $\begin{array}{l}3,4 \\
6,6 \\
7,9 \\
4,1\end{array}$ & $\begin{array}{l}6,9 \\
6,0 \\
6,0 \\
7,1\end{array}$ & $\begin{array}{l}15,1 \\
12,0 \\
45,1 \\
13,3\end{array}$ & $\begin{array}{l}0,14 \\
0,11 \\
0,32 \\
0,13\end{array}$ \\
\hline $\begin{array}{l}\text { Сырье промыш- } \\
\text { ленной установ- } \\
\text { ки }\end{array}$ & $\begin{array}{l}\text { Без добавки } \\
\mathrm{C} \text { бензином полукоксования } \\
\mathrm{C} \mathrm{Fe}_{2} \mathrm{O}_{3} \\
\mathrm{C} \mathrm{Ni}\end{array}$ & $\begin{array}{l}2,1 \\
3,0 \\
5,9 \\
2,9\end{array}$ & $\begin{array}{l}4,0 \\
2,5 \\
1,9 \\
3,0\end{array}$ & $\begin{array}{l}20,1 \\
15,8 \\
21,0 \\
20,0\end{array}$ & $\begin{array}{l}0,12 \\
0,10 \\
0,13 \\
0,14\end{array}$ \\
\hline
\end{tabular}

Для количественной оценки хода пиролиза сравнивали интегральные интенсивности характерных областей ПМР-спектров пиролизатов: полиароматических (8-7,5 м. д.) и ароматических (7,5-6,6 м. д.), олефинов $\left(6,6-4,2\right.$ м. д.) и сигналов, отвечающих группам $\mathrm{CH}_{2}(\mathrm{Ar}), \mathrm{CH}_{3}(\mathrm{Ar})$, $\mathrm{CH}\left(4,2-6,25\right.$ м. д.) и $\mathrm{CH}_{2}, \mathrm{CH}_{3}(7,25-6,25$ м. д. $)$.

С целью получения сопоставимых количественных данных интегральные интенсивности выбранных областей спектра вычисляли в процентах относительно общего содержания водорода в пробе (максимального подъема линии интеграла).

Исследование зависимости между образованием кокса при пиролизе гексана, гептана, октана, нонана, пиперилена и головной фракции пиролизных смол от наличия в реакционной зоне катализаторов коксообразования $\mathrm{Fe}_{2} \mathrm{O}_{3}$ и $\mathrm{Ni}$ и ингибитора - бензина полукоксования - показало (табл. 1), что характер деструктивных процессов для ряда парафиновых углеводородов в присутствии добавок одинаков. Выход кокса мало изменяется в условиях ингибирования сланцевого бензина полукоксования. Степень разложения его увеличивается в присутствии $\mathrm{Fe}_{2} \mathrm{O}_{3}$ в 3-4 раза и незначительно в присутствии никеля.

Данные о степени деструкции хорошо согласуются с анализами на содержание водорода в пиролизном газе, полученном в опытах с рядом парафинов: наибольшие выходы кокса на окиси железа сопровождаются максимальным выходом водорода, а незначительная деструкция на никеле и в условиях ингибирования соответствует уменьшению содержания водорода в пирогазе. 
Зависимость образования различных структур в пиролизате от условий пиролиза и характера пиролизуемых продуктов

\begin{tabular}{|c|c|c|c|}
\hline Сырье & Условия & $\begin{array}{c}\text { Образование } \\
\mathrm{CH}-, \mathrm{CH}_{3}(\mathrm{Ar})- \\
\text { и } \mathrm{CH}_{2}(\mathrm{Ar})- \\
\text { протонов, \% }\end{array}$ & $\begin{array}{c}\text { Образование } \\
\mathrm{CH}_{2} \text { (цепей) - и } \\
\mathrm{CH}_{3} \text { (концевых) } \\
\text { протонов, \% }\end{array}$ \\
\hline Гексан & $\begin{array}{l}\text { Без добавки } \\
\text { С бензином полукоксования } \\
\mathrm{C} \mathrm{Fe}_{2} \mathrm{O}_{3} \\
\mathrm{C} \mathrm{Ni}\end{array}$ & $\begin{array}{l}22,5 \\
24,0 \\
23,9 \\
16,8\end{array}$ & $\begin{array}{r}13,8 \\
10,6 \\
26,2 \\
9,3\end{array}$ \\
\hline Гептан & $\begin{array}{l}\text { Без добавки } \\
\mathrm{C} \text { бензином полукоксования } \\
\mathrm{C} \mathrm{Fe}_{2} \mathrm{O}_{3} \\
\mathrm{C} \mathrm{Ni}\end{array}$ & $\begin{array}{l}16,8 \\
21,1 \\
24,5 \\
13,9\end{array}$ & $\begin{array}{l}45,0 \\
13,1 \\
41,9 \\
29,5\end{array}$ \\
\hline Октан & $\begin{array}{l}\text { Без добавки } \\
\text { C бензином полукоксования } \\
\mathrm{C} \mathrm{Fe}_{2} \mathrm{O}_{3} \\
\mathrm{C} \mathrm{Ni}\end{array}$ & $\begin{array}{l}20,5 \\
20,5 \\
20,4 \\
17,9\end{array}$ & $\begin{array}{l}32,0 \\
26,0 \\
43,8 \\
26,0\end{array}$ \\
\hline Нонан & $\begin{array}{l}\text { Без добавки } \\
\text { С бензином полукоксования } \\
\mathrm{C} \mathrm{Fe}_{2} \mathrm{O}_{3} \\
\mathrm{C} \mathrm{Ni}\end{array}$ & $\begin{array}{l}15,9 \\
19,6 \\
24,0 \\
15,5\end{array}$ & $\begin{array}{l}35,0 \\
18,3 \\
41,9 \\
28,1\end{array}$ \\
\hline Пиперилен & $\begin{array}{l}\text { Без добавки } \\
\text { С бензином полукоксования } \\
\mathrm{C} \mathrm{Fe}_{2} \mathrm{O}_{3} \\
\mathrm{C} \mathrm{Ni}\end{array}$ & $\begin{array}{l}19,1 \\
18,2 \\
20,0 \\
19,2\end{array}$ & $\begin{array}{l}5,0 \\
3,0 \\
7,9 \\
1,0\end{array}$ \\
\hline $\begin{array}{l}\text { Сырье промыш- } \\
\text { ленной уста- } \\
\text { новки }\end{array}$ & $\begin{array}{l}\text { Без добавки } \\
\mathrm{C} \text { бензином полукоксования } \\
\mathrm{C} \mathrm{Fe}_{2} \mathrm{O}_{3} \\
\mathrm{C} \mathrm{Ni}\end{array}$ & $\begin{array}{l}16,2 \\
11,8 \\
14,3 \\
13,7\end{array}$ & $\begin{array}{l}3,6 \\
1,6 \\
3,5 \\
3,5\end{array}$ \\
\hline
\end{tabular}

Таблица 3

Пиролиз бензола в зависимости от условий опыта

\begin{tabular}{l|c|c|c}
\hline \multicolumn{1}{c|}{ Условия } & $\begin{array}{r}\text { Выход } \\
\text { кокса, \% }\end{array}$ & $\begin{array}{c}\text { Выход водо- } \\
\text { рода, моль } \\
\text { пирогазе, \% } \% \\
\text { на моль бен- } \\
\text { зола }\end{array}$ \\
\hline Без добавки & 0,08 & 73,3 & 0,03 \\
$\mathrm{C}$ бензином полукоксования & 1,4 & 73,6 & 0,02 \\
$\mathrm{C} \mathrm{Fe}_{2} \mathrm{O}_{3}$ & 1,8 & 76,2 & 0,04 \\
$\mathrm{C} \mathrm{Ni}$ & 32 & 93,1 & 0,41
\end{tabular}

Анализ ПМР-спектров пиролизата парафиновых углеводородов указывает на то, что в присутствии сернистых соединений и никеля идут реакции образования ароматических соединений, а наличие в реакционном пространстве окиси железа снижает ароматизацию пиролизата, но увеличивает содержание $\mathrm{CH}_{2}$ (цепи) и $\mathrm{CH}_{3}$ (концевые), а также $\mathrm{CH}$, $\mathrm{CH}_{2}(\mathrm{Ar}), \mathrm{CH}_{3}(\mathrm{Ar})$ (табл. 2). С точки зрения коксообразования большой интерес представляет содержание полиароматических протонов в пиролизате. Общая тенденция в их образовании остается той же, что и для ароматических протонов, за исключением гексана, в пиролизате кото- 
poro содержание полиароматики практически не менялось в условиях наших опытов.

Для представителя класса непредельных углеводородов - пиперилена - характерны те же закономерности термической деструкции, что и для парафинов.

При среднетемпературном пиролизе бензола в условиях катализа и ингибирования происходят явления, значительно отличающиеся от описанных выше. В присутствии никеля степень разложения бензола достигает $32 \%$, а выход водорода в пиролизном газе - 93,1\% (табл. 3 ).

Из [5] известно, что разложение ароматических углеводородов до кокса идет по пути многократной дегидроконденсации с образованием полиароматических продуктов по схеме:

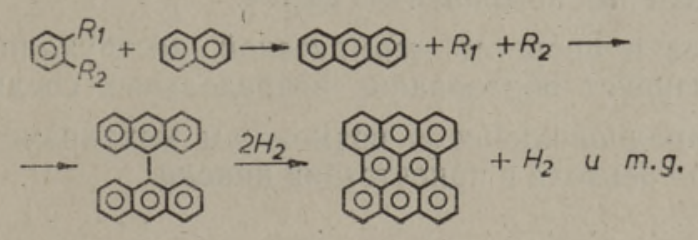

Значительное разложение бензола в присутствии никеля давало основание ожидать увеличения содержания полиароматических углеводородов в его пиролизате. К сожалению, подробная обработка спектров ПМР пиролизата бензола оказалась невозможной из-за сильного фонового сигнала ароматики, поэтому для определения содержания полициклических соединений мы прибегли к УФ-спектроскопии. Как известно, эти соединения имеют ярко выраженный пик поглощения в области 320 нм. Анализ УФ-спектров, выполненных на приборе СФ-26, показал, что в присутствии никеля содержание полиароматических углеводородов в пиролизате бензола остается таким же, как и в опытах без добавок или с добавками серусодержащих соединений и окисла железа (рис. 2). Әто может быть связано либо со значительным ускорением никелем реакций поликонденсации и образованием продуктов, не выходящих из реактора в зону конденсации, либо с прямым распадом молекул бензола на никеле.

Смесь углеводородов, являющаяся промышленным сырьем и состоящая в среднем из $50 \%$ ароматических и $50 \%$ суммы парафинов, олефинов, диенов и нафтеновых углеводородов, проявляет не вполне аддитивные свойства, но в среднем пиролизуется в соответствии с изложенными выше закономерностями для отдельных представителей, входящих в качестве компонентов в ее состав.

Рис. 2. УФ-спектры пиролизатов: в присутствии никеля (1), без добавки (2), с добавкой бензина полукоксования (3), в присутствии окиси железа (4).

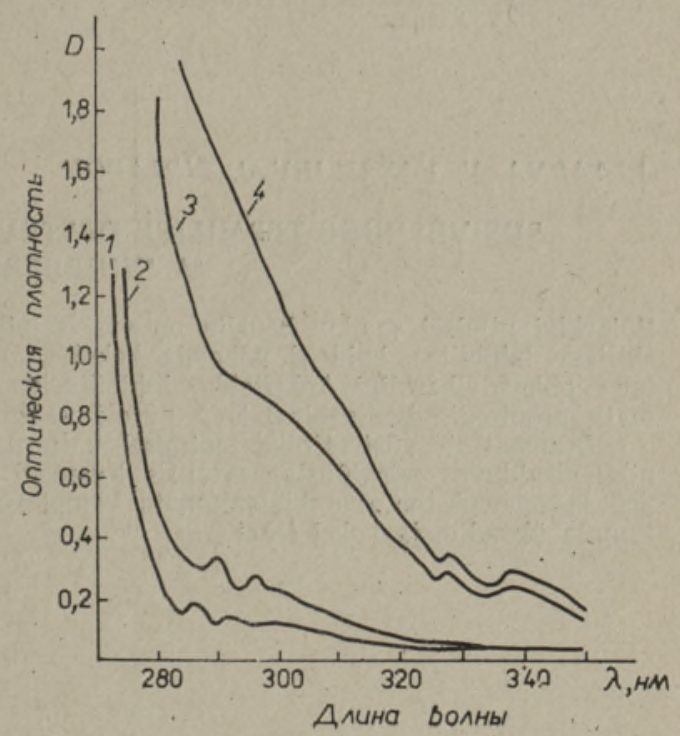




\title{
Выводы
}

1. Сланцевый бензин полукоксования, являющийся активным ингибитором коррозии при пиролизе углеводородного сырья, не снижает выход кокса. Ето влияние на процесс термической деструкции углеводородов определяется снижением концентрации ненасыщенных протонов в пиролизате. Возможность иопользования его в качестве ингибитора коррозии в промышленных условиях затрудняет повышенное образование пироуглерода.

2. При пронзводстве ароматических углеводородов способом пиролиза следует учитывать, что использование никельсодержащего оборудования приводит к потерям бензола и повышенному коксообразованию в технологической системе. Кроме того, в присутствии никеля идет разрушение непредельных компонентов сырья.

3. Окись железа в процессе термической деструкции углеводородов активно катализирует образование непредельных соединений и кокса.

4. Высказано предположение о возможном механизме коксообразования при пиролизе бензола в присутствии никеля.

\section{ЛИ ТЕРА Т УРА}

1. Аарна А. Я., Жиряков Ю. Н. Влияние состава труб пирозмеевика на процесс коксообразования при пиролизе НТРС. - ЦНИИТЭнефтехим, 1982, № 1, 12-13 (серия «Эксплуатация, модернизация и ремонт оборудования в нефтеперерабатывающей и нефтехимической промышленности»).

2. Аарна А. Я., Жиряков Ю. Н., Сооне Ю. Х. Изучение механизма коксообразования в процессе пиролиза. - Горючие сланщы, 1979, № 12, 1-6.

3. Аарна А. Я., Жиряков Ю. Н., Сооне Ю. Х. Влияние окислов железа на механизм пиролиза углеводородов. - Ж. прикл. хим., 1978, № 6, 1417.

4. Тедер Ю. T. Образование углеродов на поверхности металлов при пиролизе углеводородных смесей из ароматического и непредельного компонентов. Автореф. канд. дис. Таллин, 1980.

5. Sakai, T., Nakatani, T., Takahashi, N., Kanugi, T. - Ind. Eng. Chem. Fundam., $1972,11, \mathrm{~N} 4,529$.

\author{
Ннститут химии \\ Академии наук Эстонской ССР \\ НИИ сланцев \\ ПО «Сланцехим» им. В. И. Ленина
}

Поступила в редакцию $27 /$ IV 1983

\section{A. AARNA, V. VASSILJEV, J. ZIRJAKOV}

\section{SOSIVESINIKE TERMILISE DESTRUKTSIOONI KATALUOSIMISEST JA INHIBEERIMISEST}

Põlevkivi utmisel saadav bensiin on süsivesinike pürolüüsil pürolüüsiseadme korrosiooni aktiivne inhibiitor, kuid ei vähenda koksi saagist. Seetōttu on vähe väliavaateid kasutada põlevkivibensiini koksitekke inhibiitorina. Tema toimel tõuseb eelkōige küllastumata prootonite kontsentratsioon pürolüsaadis.

Aromaatsete süsivesinike tootmisel nafta tooraine sekundaarsel pürolüüsil põhjustab nikli sisalduvus pürolüüsiaparatuuris benseeni kadu, sest suureneb koksiteke. Nikli toimel lagunevad tooraine küllastumata komponendid, rauaoksiidi lisand pöhjustab küllas: tumata ühendite ja koksi teket. 


\section{A. AARNA, V. VASSILYEV, Y. ZHIRYAKOV}

\section{CATALYSIS AND INHIBITION OF THE THERMAL DESTRUCTION OF HYDROCARBONS}

Gasoline produced during the semicoking of oil shales is an active corrosion inhibitor for hydrocarbons plants, but it does not repress coke formation. Therefore this gasoline has few prospects to be used as a coke formation inhibitor. It influences primarily the concentration of unsaturated protons in pyrolysis products.

Nickel as an ingredient of pyrolysis plant equipment induces benzene losses due to an increase in the coke yield in the production of aromatic hydrocarbons from secondary naphtha feedstocks. The presence of nickel causes a destruction of unsaturated feedstock components. Iron oxide gives rise to the formation of coke and unsaturated compounds. 